\title{
PEMANFAATAN HASIL PRODUKSI COCOPEAT UNTUK PENGEMBANGAN UKM
}

\author{
Anita Syafariah ${ }^{1}$, Yushar Kadir ${ }^{2}$, M. Ryanto ${ }^{3}$, Rudy Gunawan ${ }^{4}$ \\ 1,2,3,4 Universitas Sangga Buana Bandung \\ ${ }^{1}$ korespondensi : anita.syafariah@usbypkp.ac.id
}

\begin{abstract}
ABSTRAK
Dalam memproduksi suatu produk, biasanya ada limbah yang kurang termanfaatkan bahkan cenderung diabaikan. Padahal limbah tersebut dapat dimanfaatkan supaya bernilai ekonomi. Sebagai salah satu contoh di Dusun Sidahurip Desa Cintakarya Kecamatan Parigi Pangandaran Jawa Barat, limbah dari serabut kelapa (coco fiber) dan serbuk sabut kelapa (cocopeat). Limbah-limbah trersebut dapat dimanfaatkan berupa asesoris atau pernak pernik atau kerajinan tangan lain, sehingga berdaya jual tinggi. Tim Pengabdian Kepada Masyakarat (PKM) Dosen Tetap Fakultas Teknik Universitas Sangga Buana (USB) YPKP Bandung, berencana akan memanfaatkan limbah tersebut dijadikan Produk olahan atau kreatifitas yang berasal dari serbuk sabut kepala seperti : Frame (Pigura), alat untuk menyimpan paku softboard/jarum pentul, polybag, pot bunga, asbak, tatakan gelas, tatakan panci, dan sebagai media tanam. Dan dilihat dari proses pengerjaannya tidak terlalu memerlukan biaya besar dan waktu yang lama, tergantung pada karyawan yang akan mengerjakannya. Untuk kegiatan Pengabdian Kepada Masyarakat (PKM) yang akan datang, kami tim akan lebih fokus kepada pembuatan polybag. Yang didalamnya akan dirinci bagaimana membuat polybag yang ramah lingkungan dengan pembiayaan yang efisien dan waktu yang efektif serta harga jual yang bersaing.
\end{abstract}

Kata Kunci : Cocopeat, Limbah, Kerajinan Tangan

\begin{abstract}
In producing a product, usually there is waste that is underutilized and even tends to be ignored. Even though this waste can be used for economic value. As one example in Sidahurip Hamlet, Cintakarya Village, Parigi Pangandaran District, West Java, waste from coconut fibers (coco fiber) and coconut coir powder (cocopeat). These wastes can be used in the form of accessories or knick-knacks or other handicrafts, so that they have high selling power. The Community Service Team (PKM), Permanent Lecturer at the Faculty of Engineering, Sangga Buana University (USB) YPKP Bandung, plan to use this waste as processed products or creativity derived from coir powder such as: Frame (Frame), a tool for storing softboard nails / pins, polybags, flower pots, ashtrays, coasters, saucers, and as a planting medium. And seen from the process, it does not require a lot of money and time, depending on the employees who will do it. For future Community Service (PKM) activities, our team will focus more on making polybags. In which it will detail how to make environmentally friendly polybags with efficient and time-effective financing and competitive selling prices.
\end{abstract}

Keywords: Cocopeat, Waste, Craft

\section{PENDAHULUAN}

Indonesia merupakan salah satu negara penghasil buah kelapa terbesar di dunia [1]. Dengan demikian akan semakin banyak buah kelapa, semakin banyak pula limbah sabut kelapa yang menumpuk khususnya pada saat musim panen tiba. Banyaknya limbah sabut buah kelapa akan menjadi tempat bersarangnya ulat dan ular. Tidak menutup kemungkinan sabut kelapa yang hanya ditumpuk dan tidak dikelola hanya akan mencemari lingkungan menjadi bau, kumuh dan kotor.

Sebagian petani memilih untuk memusnahkan, membuang dan membakar limbah sabut kepala tersebut. Sebagian pengrajin mengolah dan memberi nilai tambah pada limbah sabut supaya memberikan dampak positif bagi kelestarian alam. 
P-ISSN: 2745-5912

E-ISSN: 2745-9047

Disisi lain semua turunan kelapa memiliki nilai ekonomis yang tinggi. Mulai dari buah kelapanya, batang kelapa yang biasanya digunakan untuk bahan bangunan, tempurung kelapa digunakan sebagai hiasan atau souvenir dan daunnya untuk menghasilkan sebuah lidi [2]. Untuk serbuk sebut kelapanya kerap kali dibuang atau hanya untuk kayu bakar.

Sabut kelapa yang melimpah perlu digali menjadi sebuah inovasi sehingga bermanfaat dan memiliki daya tarik tersendiri untuk membuat produk olahan atau kreatifitas [3]. Produk olahan atau kreatifitas dari sabut kelapa (coco fiber) tersebut dapat berupa asesoris atau pernak pernik seperti : keset, tas, topi, sandal, pot, coconet, bantal, guling, dan kasur. Untuk serbuk sabut kepala dapat dijadikan Frame (Pigura), alat untuk menyimpan paku softboard/jarum pentul, polybag, pot bunga, asbak, tatakan gelas, tatakan panci, dan sebagai media tanam [4].

Berdasarkan dari hasil survey yang dilaksanakan pada tanggal 10-11 Oktober 2017, maka Tim bermaksud untuk melaksanakan Pengabdian Kepada Masyarakat dengan kajian "Pemanfaatan Hasil Produksi Cocopeat untuk Pengembangan UKM di Dusun Sidahurip Desa Cintakarya Kecamatan Parigi Pangandaran Jawa Barat"

\section{METODE}

Metode pelaksanaan pada kegiatan Pengabdian Kepada Masyarakat (PKM) adalah Praktek langsung kepada karyawan Koperasi Mitra Malabar Pangandaran.

Adapun proses pengerjaannya adalah sebagai berikut :

I. Persiapan

Mempersiapkan bahan dan alat

a. Bahan :

1. Cocopeat

2. Lem kayu

3. Minyak kelapa

b. Alat (cetakan) :

1. Tatakan gelas

2. Paralon

3. Plat (besi/kayu)

4. Alat pengepres

II. Proses

1. Siapkan cocopeat sekitar $1 / 8$ bagian, haluskan

2. Campurkan cocopeat dengan lem kayu sekitar 50 gram

3. Masukan adonan sesuai dengan cetakan

4. Keluarkan adonan dari cetakan setelah 3-5 menit

Untuk lebih jelasnya dapat dilihat pada gambargambar berikut : 
P-ISSN: 2745-5912

E-ISSN: 2745-9047

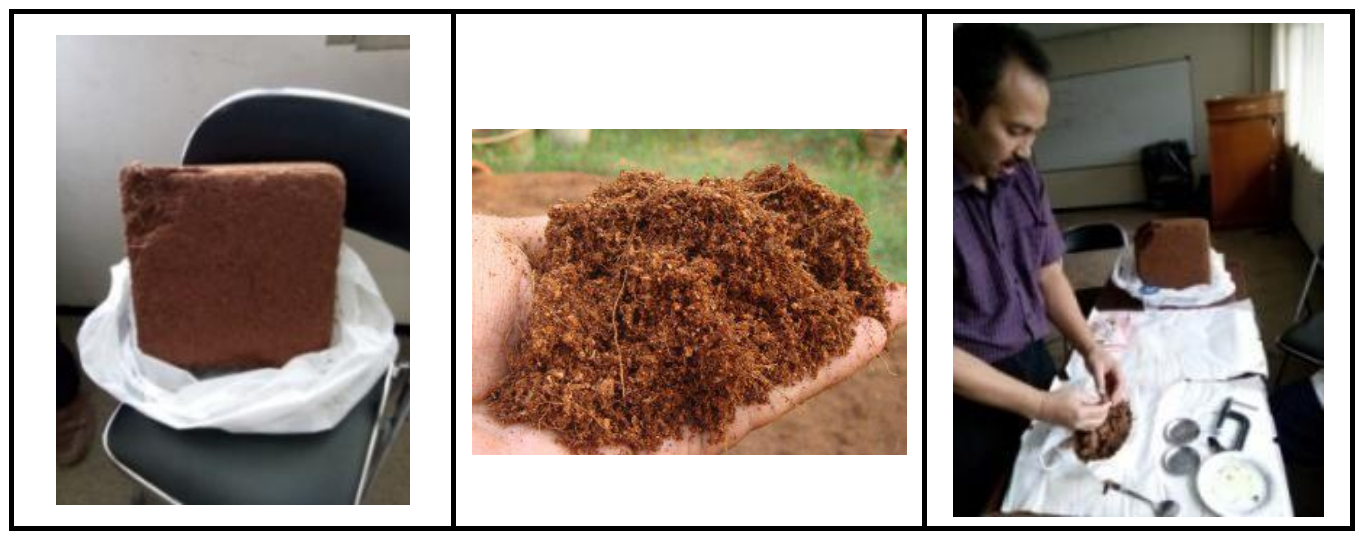

Gambar 1 : Penghalusan Cocopeat

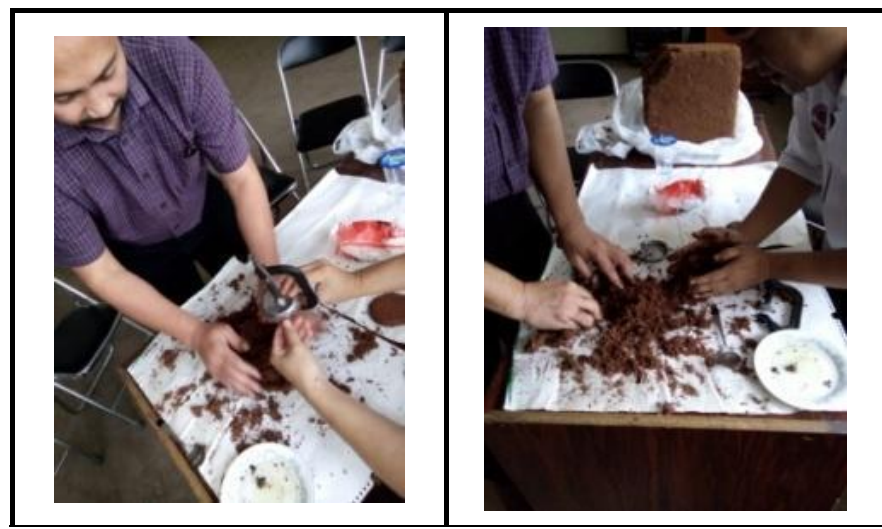

Gambar 2 : Pengadukan cocopeat dan lem kayu

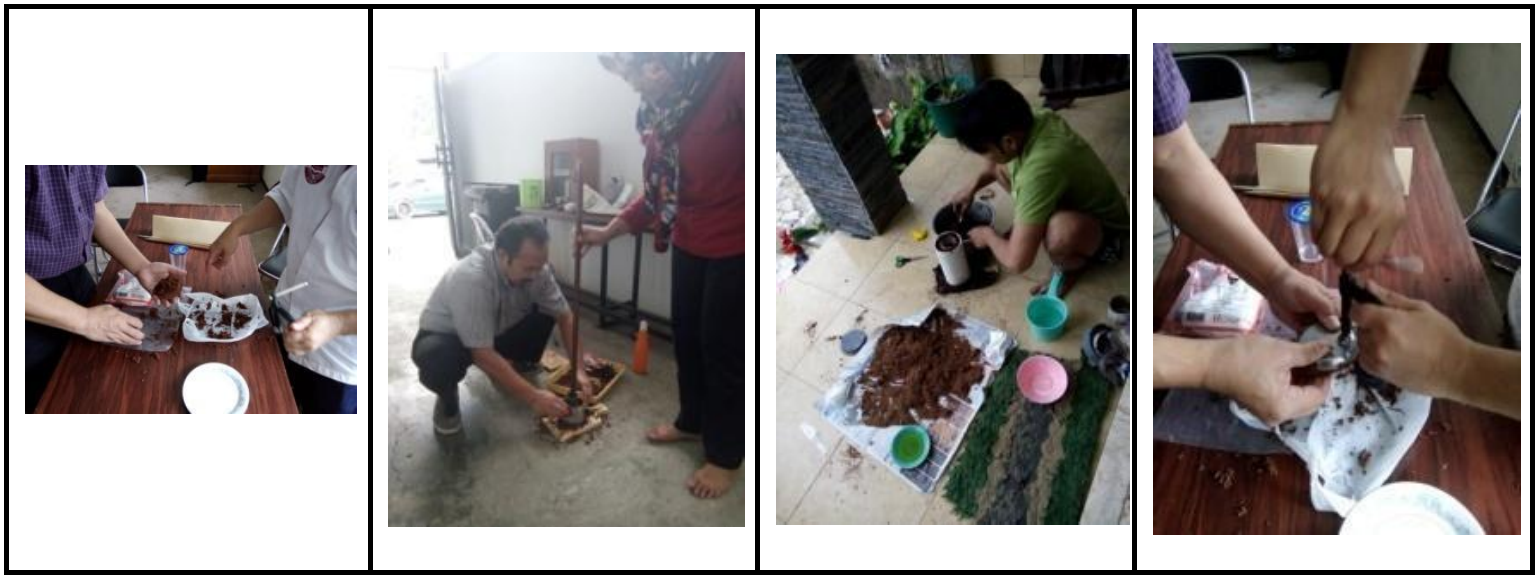

Gambar 3 : Pencetakan Adonan 


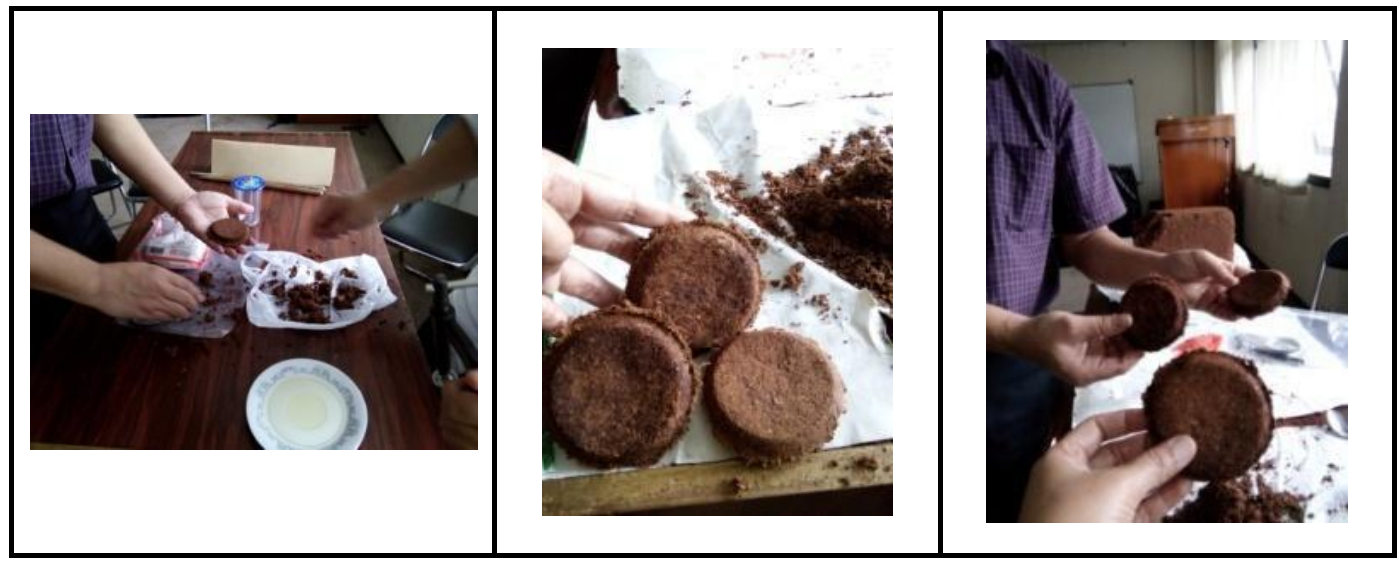

Gambar 4 : Adonan yang sudah tercetak

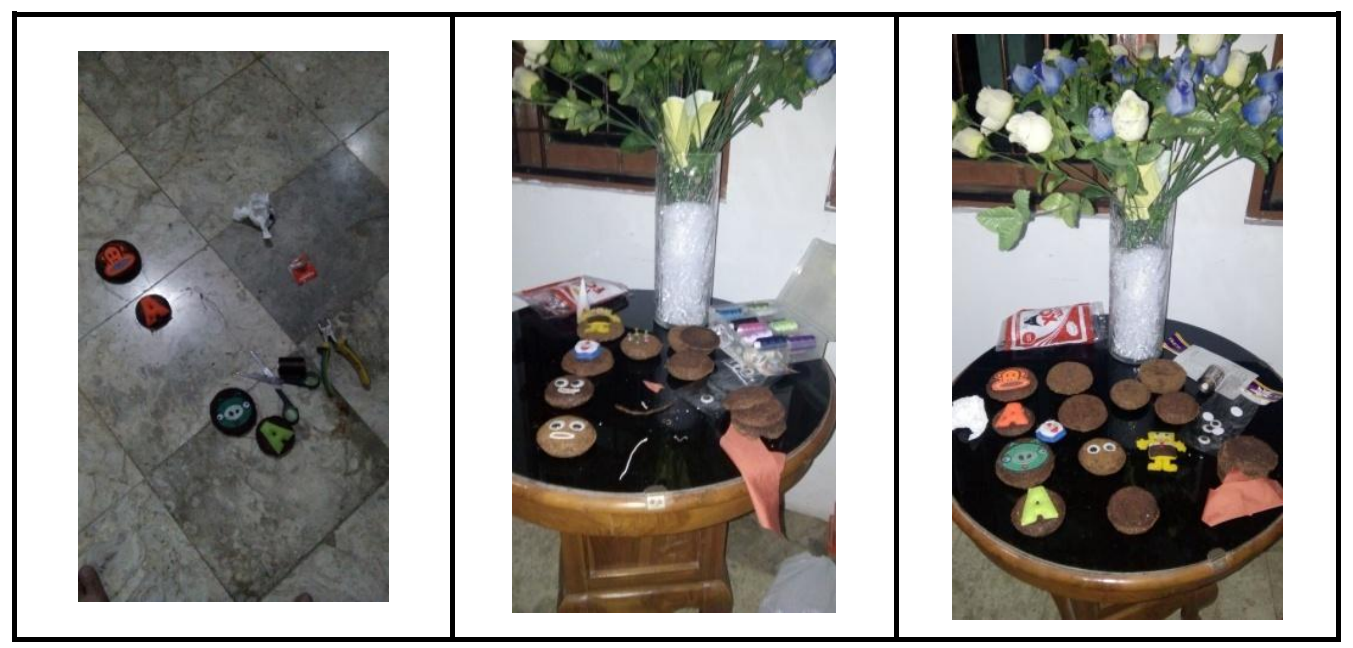

Gambar 5: Hasil Produk Cocopeat

\section{HASIL DAN PEMBAHASAN}

Hasil dari pelaksanaan kegiatan Pengabdian Kepada Masyarakat (PKM) Tim Dosen Fakultas Teknik dengan pihak Pengurus dan karyawan Koperasi Mitra Malabar di Dusun Sidahurip Desa Cintakarya Kecamatan Parigi Pangandaran Jawa Barat adalah sebagai berikut :

1. Membuat mesin cetakan polybag yang efektif dan efisien

2. Membuat dan mendesign alat pengepres untuk pembuatan polybag berbahan serbuk sabut kelapa sebagai media tanam
3. Menghitung Break event Point dalam memproses dan menjual polybag

Dalam melaksanakan Pengabdian Kepada Masyarakat (PKM) kami dari Tim mendapatkan banyak ide-ide untuk memanfaatkan cocopeat tersebut, tetapi kami mendapat kendala dengan cetakan yang akan dipergunakan dan belum ada kesepakatan kerajinan apa yang akan dipasarkan di Dusun Sidahurip Desa Cintakarya Kecamatan Parigi Pangandaran Jawa Barat tersebut.

Namun dengan demikian dari pihak Pengurus Koperasi Mitra Malabar memberikan inspirasi yaitu membuat polybag yang sasarannya 
adalah petani baik di dalam maupun di luar dusun Sidahurip karena pihak pengurus koperasi telah melakukan survey dan akan menindaklanjuti kerjasama dengan para petani mengenai pengadaan polybag tersebut. Sehubungan dengan inspirasi tersebut dan adanya keterbatasan mengenai dana, maka kami Tim berencana akan membuat proposal hibah tentang PKM tahap 2 yaitu dengan menyumbangkan Mesin Pencetak Polybag yang efektif dan efisien dengan harga yang bersaing.

\section{PENUTUP}

Hasil kegiatan Penelitian dan Pengabdian Kepada Masyarakat (PKM) ini adalah Koperasi Mitra Malabar Pangandaran ini dapat berkembang jika didukung dengan alat, sumber daya manusia dan biaya yang cukup memadai.

Dilihat dari keseluruhan pabrik tempat produksi masih banyak yang harus dibenahi seperti :

1. Tata letak untuk tiap bagian kerja yang kurang nyaman dalam bekerja
2. Faktor kebersihan

3. Alat-alat produksi yang masih sangat minim dan tradisional

4. Pemanfaatan limbah-limbah produksi yang belum terolah menjadi suatu karya seni atau nilai tambah bagi pihak koperasi

Untuk itu, kami Tim Pengabdian Masyarakat yang akan membantu dan mengarahkan dalam hal tersebut diatas.

Pengadaan mesin dan tatacara pengoperasan mesin yang diharapkan oleh pihak pengurus dan karyawan Koperasi Mitra Malabar Pangandaran untuk mempermudah dan mempercepat serta berhasil guna.

\section{DAFTAR PUSTAKA}

[1] www.urbanina.com (diakses pada 18 Desember 2017)

[2] http://id.wikipedia.org/wiki/Sabut (diakses pada: 07 Maret 2014)

[3] http://id.wikipedia.org/wiki/Sabut (diakses pada: 07 Maret 2014)

[4] www.cocopeat.com (diakses pada 18 Desember 2017) 